\title{
The myocardial microcirculation: A key target for salvaging ischemic myocardium?
}

\author{
John G. Kingma \\ Département de Médecine, Pavillon Ferdinand-Vandry 1050, Université Laval Québec, Québec, Canada \\ Email: john.kingma@fmed.ulaval.ca
}

Received 27 June 2013; revised 27 July 2013; accepted 30 July 2013

Copyright (C) 2013 John G. Kingma. This is an open access article distributed under the Creative Commons Attribution License, which permits unrestricted use, distribution, and reproduction in any medium, provided the original work is properly cited.

\begin{abstract}
Clinical management of patients with acute myocardial infarction for the most part involves re-opening of an infarct-related coronary vessel by the use of clot-busting pharmacologic treatment or percutaneous coronary interventions. While blood flow in the epicardial coronary vessel is restored downstream, effects remain largely unexplored; progressive injury at the microvessel level has significant repercussions on restoration of cardiocyte viability and the ventricular blood flow and contractile function relationship. This review focuses on the cardiac microcirculation and the fact that it should be a principle target of future studies to permit improvement of clinical outcomes in patients presenting with evolving myocardial infarction.
\end{abstract}

Keywords: Microcirculation; Ischemia; Reperfusion; Blood Flow; Cardioprotection

\section{INTRODUCTION}

Cardiovascular disease currently generates billions of dollars in healthcare costs globally and accounts for the majority of deaths and disability worldwide. Principle complications of cardiovascular diseases include myocardial infarction and subsequent ventricular contractile failure. Acute myocardial infarction occurs subsequent to sudden obstruction of coronary blood flow (i.e. ischemia due to coronary thrombus or embolus) to a specific region of the heart muscle. The duration of blood flow deficit ultimately determines the overall level of cellular injury and the potential for recovery of function of affected myocardium. With prolonged ischemia a "wavefront" of cell death, commencing from the innermost (endocardium) to the outermost (epicardium) layer of the ventricular wall develops until a fully transmural infarct is produced [1]. Irreversible damage also occurs to components of the myocardial microvasculature but it is not clear that damage at this level occurs prior to onset of cardiocyte necrosis [2]. Finally, damage also occurs at the level of intramyocardial nerves [3]; however, few studies have focused on this aspect of post-ischemic myocardial injury.

For patients presenting with an acute myocardial infarction, various reperfusion strategies have been developed in an attempt to delay progression of or to reduce ultimate infarct size, improve recovery of ventricular contractile function, limit onset of heart failure and improve clinical outcomes. Paradoxically, restoration of blood flow to the infarct-related coronary artery, though critical for myocardial salvage, could produce further injury to already damaged (and even previously undamaged) cardiocytes and thereby mitigate the potential benefits of "reperfusion therapy"; this phenomenon is more widely referred to as myocardial reperfusion injury [4-7]. Within this context various phenomenon including, reperfusioninduced arrhythmias, myocardial stunning, microvessel obstruction and lethal reperfusion injury are currently acknowledged [8]. Compromised blood flow at the level of the microvasculature is generally associated with larger infarcts, reduced cardiac contractile performance, adverse LV remodelling and poor clinical outcomes $[9,10]$. This review focuses on the cardiac microcirculation and whether it should be targeted to permit improvement of clinical outcomes in patients presenting with evolving myocardial infarction.

\section{PHYSIOPATHOLOGY OF THE MICROCIRCULATION}

Delivery of oxygen and nutrients to tissues in each organ is the ultimate function of the cardiovascular system. The architecture of the microcirculation includes arterioles, capillaries and venules $[11,12]$. Crucial exchange processes for oxygen, nutrients and hormones all occur at the level of the microcirculation; metabolic catabolites are also removed here. In addition, during inflammation an- 
tibodies, fibrinogen, elements of the complement system and inflammatory cells all enter injured tissues at the level of the microcirculation. Chemical and physical factors that regulate microvessel functions have been widely investigated; a specific focal point has been the production of endogenously produced compounds that could affect endothelial cells or underlying smooth muscle cells in different disease processes [13-15].

In the heart, the microcirculation comprises a dense intramyocardial network of microvessels that originate from a proximal arterial system [16]. The latter is divided into three compartments: 1) epicardial coronary (conductive) arteries, 2) pre-arterioles and 3) intramural arterioles; each of these compartments has the capacity to modulate capacitance and tone so that blood flow is matched to oxygen requirements $[17,18]$. Krogh first described the regulation of the capillary circulation in relation to tissue oxygen supply [19], and showed in the heart that during exercise (with an increase in oxygen demand) capillary vessels could be recruited to enable adequate distribution of blood flow. A small number of coronary capillaries are open under resting conditions in the heart; when oxygen demand is higher additional capillaries are recruited. In the setting of coronary artery disease vasodilatory capacity of the microvasculature is reduced and aerobic threshold (i.e. critical equilibrium between oxygen supply and demand) of ischemic myocardium is reached much sooner. Metabolic, neural and myogenic mechanisms regulate blood flow within the vascular network; higher blood flows require a corresponding increase in vessel diameter particularly at the level of the microvasculature.

Cardiocyte viability post-ischemia is integrally linked to the ability of the microvasculature to deliver oxygen and nutrients either via pre-existing coronary or collateral networks or promotion of new vessel growth (arteriogenesis). Transmural distribution of coronary collaterals varies considerably between species and is genetically determined [20,21]; consequently, post-ischemic development of cardiocyte injury is directly dependent on the location of functional collateral vessels across the ventricular wall. Development of functional collateral vessels cannot be predicted in advance of an acute coronary event; neither can we predict which patients have the ability to develop collateral vessels after an acute insult [22]. However, an extended time frame is necessary for new vessel growth $[23,24]$. Existing small vessels may also undergo a process of endogenous remodeling via stimulation of molecular and cellular processes [25]. There is ample reference in the scientific literature regarding recruitment of coronary collateral vessels at the onset of ischemia. It would seem more reasonable to use the terminology of microvessel recruitment as initially suggested by Krogh [19]; questions as to whether arterial vessels recruited during the acute ischemic event are true collateral vessels or pre-existing arterioles/capillaries that open because of local changes in external influences on the myocardial wall independent of the vessels themselves is not trivial and should be addressed. External factors such as intramyocardial tissue pressure, coronary perfusion pressure and location within the ventricular wall all influence coronary collateral circulation. The functional efficacy of coronary collaterals remains controversial; clinical evidence of improved ventricular function post-ischemia remains anecdotal. On a similar note reduced infarct size, incidence of arrhythmias and mortality due to the presence of functional coronary collateral circulation remains speculative.

\section{EFFECT OF ISCHEMIA}

Acute obstruction of a coronary vessel initiates profound pathological changes in cardiocytes (within the area of no blood flow or anatomic area at risk) due to abrupt stoppage of biochemical and metabolic pathways. Reduced oxygen delivery halts oxidative phosphorylation at the mitochondrial level and leads to mitochondrial membrane depolarization, depletion of intracellular energy phosphate stores and inhibition of myocyte contractile function. Ultrastructural changes at the level of cardiocytes include cellular swelling, subsarcolemmal blebbing, cytoplasmic membrane-bound vacuoles, swollen mitochondria, nuclear chromatin clumping and margination [26]. Within the coronary vessels vascular endothelial cells become swollen and deformed with small intraluminal protrusions; these cells also demonstrate nuclear chromatin clumping and margination, fewer pinocytotic vesicles and intercellular separation [27]. The described cellular injury represents a small portion of the ultrastructure changes that occur briefly after onset of coronary occlusion. Reversibility of these ultrastructure alterations is possible but entirely dependent on duration of the ischemic insult. Mechanisms responsible for abnormal blood flow to damaged myocardium have not been clearly established; capillary damage and external capillary compression due to edema, micro-embolization of microthrombi from atherosclerotic plaque or platelet aggregation and neutrophil plugging remain potential candidates for poor transmural distribution of blood flow [28-30].

For patients presenting with cardiac symptoms reducing the time from chest pain onset to arrival at the hospital coronary intervention unit remains the first priority. In the pre-hospital phase different ambulatory therapeutic strategies have been shown with varying degrees of success to delay development of cardiocyte injury. Most pharmacologic compounds have not yet shown consistent benefit with respect to reduction of ischemic injury, preserving cardiac function and improving patient outcomes; 
the reasons for the poor performance are currently the subject of debate and ongoing research [31,32]. Timely restoration of blood flow to an infarct-related artery may be the most effective strategy to limit ischemic injury and cardiocyte necrosis. While a host of experimental and clinical studies have reported that it is possible to limit development of post-ischemic myocardial injury [32-35], for the most part a delay and not a reduction of ultimate infarct size has been demonstrated. No pharmacologic treatment has been shown to sufficiently limit infarct size; potential reasons being; 1) timing of administration and dosage of potentially cardioprotective treatments, and 2) heterogeneity of comorbidities within the patient populations [36].

Myocardial infarction produces a persistent reduction in contractile function due to loss of cardiocytes and replacement by fibrotic tissue [33]. Even when ischemia is alleviated by restoration of blood flow to the infarctrelated artery before the onset of irreversible cardiocyte death contractile dysfunction can persist - this is more commonly referred to as "myocardial stunning" [37,38]. When myocardium is subjected to repetitive reversible ischemia over an extended period cardiocyte remodelling can occur at both the cellular and molecular levels [39]. Within the ischemic zone viable chronically dysfunctional myocardium has also been reported in the absence of persistent perfusion abnormalities-this is commonly referred to as "myocardial hibernation" [40-42]. While loss of cardiocytes and cellular hypertrophy play a role in persistent ventricular contractile dysfunction pathologic fibrosis to replace necrotic cardiocytes within the ischemic zone is also important [43]. The extent of pathophysiological remodeling that occurs is partly dependent on the degree of coronary perfusion to the ischemic vascular bed [44]; reductions in blood flow could result in activation of endogenous metabolic pathways that could result in a down-regulation of myocardial oxygen requirements $[39,45,46]$. Cellular adaptive mechanisms such as down-regulation of mitochondrial proteins or up-regulation of stress and cytoskeletal proteins all impact the ability of the failing heart to adjust to changes in cardiac workload [47,48]. Additional studies are needed to understand cardiocyte as well as vascular remodeling after restoration of blood flow to an infarct-related coronary artery.

Transient ischemia produces persistent regional cardiac contractile dysfunction even in the absence of cardiocyte necrosis [49-53]. A direct relation has been reported between blood flow and contractile function [50]; this relation is superimposable at rest and during exercise under normal conditions (i.e. no underlying coronary artery disease) [53,54]. We recently documented, in canine hearts subjected to transient ischemia, that the flowfunction relation was influenced by nitric oxide bioavai- lability resulting in a perfusion-function mismatch [55].

\section{EFFECT OF REPERFUSION}

Timely opening of an infarctrelated artery is essential for the salvage of viable cardiocytes within the anatomic area at risk; however, on reperfusion vessel injury could occur resulting in local or downstream obstruction of the vessel lumen. Endothelial injury and obstruction of capillaries therefore remains a primary consideration for the success of potential reperfusion therapies. Restoration of blood flow within an infarct-related artery (i.e. conduit vessel) is generally accomplished by pharmacologic thrombolytic therapy or percutaneous angioplasty [32, 34]. While restoration of blood flow in the conduit vessel is readily observed it does not assure transmural distribution of blood flow at the level of the microvasculature. This is probably due to the transmural heterogeneity for distribution of microvascular resistance where resistance is higher in the endocardial tissue layer compared to the epicardium [56]; however, this gradient is reversed within the microcirculation [57]. Circulation to the deeper myocardial layers may remain abnormal and would probably be insufficient to maintain normal cardiocyte function and ventricular contraction [58]. We raise the question as to whether more attention should be paid in both pre-clinical and clinical studies to the role of the coronary microcirculation and its distribution across the ventricular wall on development of ischemic injury and post-ischemic ventricular remodeling. While restoration of blood flow to the vascular bed of an infarct-related artery clearly delays development of tissue necrosis this may also be a mixed blessing since additional cardiocyte damage may occur to a population of reversibly injured myocytes within the area at risk. Thus, myocardial reperfusion is often viewed in the context of being a “double-edged sword" [4].

\section{LETHAL REPERFUSION INJURY}

After successful reperfusion of an infarct-related artery further cellular necrosis could be induced in cardiocytes that were believed to be viable at the end of the ischemic event; this phenomenon is commonly referred to as lethal myocardial reperfusion injury [8]. Potential pathways responsible for lethal myocardial reperfusion injury include oxidative stress, intracellular calcium overload, rapid restoration of physiological $\mathrm{pH}$ to ischemic myocardium, dysfunctional mitochondrial permeability transition pore and inflammation. These mechanisms and their contribution to lethal myocardial reperfusion injury have recently been reviewed [8]. Whether lethal myocardial reperfusion injuries actually occur remains controversial; several studies suggest it may account for up to 50 percent of final infarct size $[6,59]$. The choice of 
reperfusion strategy may therefore impact on the overall severity of lethal reperfusion injury inasmuch as one adheres to the dogma that reperfusion can actually be detrimental to post-ischemia cardiocyte survival.

\section{NO-REFLOW}

More attention is being paid in the clinical setting to the phenomenon of "no-reflow" which results from endothelial cell injury during ischemia and develops within the ischemic vascular bed after opening an infarct-related artery. Interacting factors that contribute to no-reflow include ischemic injury, reperfusion injury, distal vessel embolization and microvessel susceptibility to injury [60]; all of these elements are associated with profound disturbances of vasoregulatory pathways [61]. Ischemiareperfusion damage is central to the physiopathology of no-reflow which results in impaired LV remodeling, ventricular dysfunction and clearly impacts survival. After opening of the infarct-related vessel regional blood flow is initially hyperemic and then progressively declines [27,62-66]; the area of no-reflow progresses across the $\mathrm{LV}$ wall from the endocardium, is constrained to the ischemic area [2,26,58], and may depend on degree of collateral blood flow to ischemic region during coronary occlusion [66]. The causal link between microvascular and myocardial damage remains to be established [62,63, 67]; reduction of no-reflow and tissue necrosis has been documented with pharmacologic interventions given at the time of reperfusion [68]. Mechanisms responsible for no-reflow are probably quite similar across species including humans and include endothelial injury, accumulation of inflammatory cells, reactive oxygen intermediates and the coagulation cascade. While no-reflow may not produce cardiocyte necrosis the overall consensus is that improvements in coronary collateral flow to the ischemic vascular bed will produce less ventricular remodeling; in a retrospective clinical study of cardiovascular disease Rezkalla et al. reported no-reflow in more than a third of patients [69]. Intracoronary pharmacologic treatment in these patients resulted in normalization of flow to ischemic myocardium and, more importantly, reduced mortality.

\section{CARDIAC CONDITIONING AND ISCHEMIC INJURY}

Cardiac conditioning represents a potential breakthrough for protection of the ischemic heart. Murry et al. initially described "ischemic preconditioning" in dogs exposed to intermittent cycles of nonlethal coronary occlusion and reperfusion prior to a period of sustained coronary occlusion [70]. In this study infarct size was consistently smaller in hearts pretreated by the conditioning stimulus prior to index ischemia; however, cardioprotection was not sustained when the duration of coronary occlusion was extended to 3 hours. Since the publication of this landmark paper a host of studies have attempted to elucidate underlying mechanisms responsible for this endogenous cellular protective phenomenon with the hope of identifying mediators amenable to pharmacologic manipulation for clinical utilisation [71-73]. In the current paradigm the conditioning stimulus generates endogenous ligands including adenosine, opioids and catecholamines that trigger cellular transduction pathways and mediate protective signals from the cell membrane to mitochondria where end-effectors induce protection [72, 74]. Although most studies have focused on protection in the heart conditioning pre-treatment protection has been reported for all organs studied [75-78]. To date, cardiac conditioning has been achieved using anesthetic, pharmacological and even remote interventions; the similarity of mechanisms forwarded for the different conditioning stimuli suggest the existence of a cross-tolerance phenomenon $[79,80]$. Even though significant progress has been made in the identification of innate protective pathways involved translation of the overall benefits of conditioning into clinical practice remains a challenge.

The key requirement for organ conditioning is reperfusion of the ischemic tissues. In humans, protection of the coronary vasculature by various conditioning manoeuvers has not been clearly established but in several reports better myocardial perfusion (higher TIMI score or myocardial blush grade and coronary flow reserve) has been reported $[81,82]$. Prevention of vessel dysfunction by cardiac conditioning remains controversial; in animal models cardiac conditioning has been shown to conserve endothelial function and increase regional myocardial blood flow [62,83-87]. Vascular injury produced by myocardial ischemia-reperfusion ranges from mild functional impairment of endothelium-dependent vasodilatation, to increased permeability and severe structural alterations to no-reflow. A recent elegant study by Skyschally et al. examined the impact of microembolization at the onset of coronary reperfusion on myocardial infarction in a porcine experimental preparation of ischemia-reperfusion [88]. They showed that no-reflow and tissue necrosis were significantly attenuated in post-conditioned animals and suggested that embolization of microvessels located primarily at the border zone (i.e. between ischemic and non-ischemic myocardium) prevented an increase in cardiocyte necrosis. Whittaker and Przyklenk previously hypothesized that the border zone was most susceptible to further damage during post-ischemic reperfusion of the infarct-related artery [89]. On the other hand, several recent clinical studies using postconditioning failed to show cardioprotection thus confirming the need for further study [90,91]. 


\section{SUMMARY AND CONCLUSIONS}

Progress has been substantial over the past several decades regarding angioplasty technologies for rapid restoration of blood flow in infarct-related conduit vessels in humans. Keeping afflicted vessels open by implantation of a coronary stent is also effective; however, considerable efforts are ongoing to limit problems associated with their use. While it is clear that these interventions are successful in the majority of patients to restore/maintain patency of conductive arteries and trigger myocardial salvage much less is known about the recovery of cardiocyte viability and distribution of blood flow within the infarct core (i.e. deeper myocardial tissue layers). In the clinical setting direct anatomical quantification of blood flow in the myocardial microcirculation remains elusive. However, coronary microvascular abnormalities could explain clinical signs of myocardial ischemia often observed in patients with normal coronary angiograms (cf. Herrmann et al. for recent review [92]). Microvessel dysfunction in patients is generally estimated by the use of vasodilator agents in conjunction with positron emission tomography or cardiovascular magnetic resonance techniques [16]. Myocardial contrast echocardiography is also used to assess microvessel perfusion [93,94]; using this technique it has been reported that microvessel obstruction occurs in 30 - 40 percent of patients with reperfused ST-elevation acute myocardial infarction in which optimal TIMI (Thrombolysis in Myocardial Infarction) flow was achieved [10]. The consensus of clinical findings with myocardial contrast echocardiography is that poor perfusion of the deeper myocardium with adequate restoration of epicardial blood flow is a primary risk factor for ventricular remodelling and major adverse cardiac events [95,96]. In addition, coronary flow reserve can be directly measured the catheterisation laboratory; Posa et al. recently documented the occurrence of microvessel obstruction immediately post-opening of the infarct-related artery in a collateral circulation poor porcine model of ischemia-reperfusion [97]. Coronary reserve is spatially variable [98-101]; myocardial regions with reduced intrinsic coronary reserve could be most vulnerable to transient, repetitive ischemic events that culminate in microareas of cardiocyte necrosis. In preclinical studies organ blood flow under diverse experimental conditions can be more readily evaluated by the use of microspheres [102]. Marked progressive reduction of blood flow and capillary filling in the canine heart following acute myocardial ischemia has been reported even after initial demonstration of adequate blood flow in epicardial coronary arteries [66,103]. Poor blood flow at the level of the microvessels could be due to increased microcirculatory resistance distal to the site of conduit vessel occlusion [104]; clinical studies have not yet evalu- ated microvessel responses or ultrastructural changes in viable but dysfunctional myocardium. It is suggested that progressive vascular remodeling of coronary resistance vessels could adversely influence acute metabolic and autoregulatory adjustments and thereby contribute to poor ventricular function.

In conclusion, protection against post-ischemic injury remains an important goal in patients with coronary artery disease. The majority of pharmacologic compounds developed to date to delay progression of ischemic injury have not shown great promise against no-flow and its consequences - this is probably due to progressive loss of microvessel function post-ischemia. Therefore appraisal of changes in the coronary microcirculation within the ischemic vascular bed is absolutely central to the maintenance of cellular viability (including cardiocytes, coronary vascular cells and cardiac nerves) and restoration of ventricular contractile function. Future pre-clinical and clinical studies must take into account post-ischemic changes occurring at the level of the myocardial microvessel network and probably most-importantly within the deeper layers of the ventricular wall. Failure to do so will undoubtedly reduce the therapeutic potential that future interventions might have for patients with acute myocardial infarction.

\section{REFERENCES}

[1] Reimer, K.A., Lowe, J.E., Rasmussen, M.M. and Jennings, R.B. (1977) The wavefront phenomenon of ischemic cell death: I. Myocardial infarct size vs. duration of coronary occlusion in dogs. Circulation, 56, 786-794. doi:10.1161/01.CIR.56.5.786

[2] Kloner, R.A., Rude, R.E., Carlson, N., Maroko, P.R., DeBoer, L.W.V. and Braunwald, E. (1980) Ultrastructural evidence of microvascular damage and myocardial cell injury after coronary artery occlusion: Which comes first? Circulation, 62, 945-952. doi:10.1161/01.CIR.62.5.945

[3] Matsunari, I., Schricke, U., Bengel, F.M., Haase, H.U., Barthel, P., Schmidt, G., Nekolla, S.G., Schoemig, A. and Schwaiger, M. (2000) Extent of cardiac sympathetic neuronal damage is determined by the area of ischemia in patients with acute coronary syndromes. Circulation, 101, 2579-2585. doi:10.1161/01.CIR.101.22.2579

[4] Braunwald, E. and Kloner, R.A. (1985) Myocardial reperfusion: A double-edged sword? The Journal of Clinical Investigation, 76, 1713-1719. doi:10.1172/JCI112160

[5] Piper, H.M., Garcia-Dorado, D. and Ovize, M. (1998) A fresh look at reperfusion injury. Cardiovascular Research, 38, 291-300. doi:10.1016/S0008-6363(98)00033-9

[6] Yellon, D.M. and Hausenloy, D.J. (2007) Myocardial reperfusion injury. The New England Journal of Medicine, 357, 1121-1135. doi:10.1056/NEJMra071667

[7] Hearse, D.J. (1977) Reperfusion of the ischemic myocardium. Journal of Molecular and Cellular Cardiology, 9, 605-616. doi:10.1016/S0022-2828(77)80357-X 
[8] Hausenloy, D.J. and Yellon, D.M. (2013) Myocardial ischemia-reperfusion injury: A neglected therapeutic target. The Journal of Clinical Investigation, 123, 92-100. doi:10.1172/JCI62874

[9] Ito, H., Okamura, A., Iwakura, K., Masuyama, T., Hori, M., Takiuchi, S., Negoro, S., Nakatsuchi, Y., Taniyama, Y., Higashino, Y., Fujii, K. and Minamino, T. (1996) Myocardial perfusion patterns related to thrombolysis in myocardial infarction perfusion grades after coronary angioplasty in patients with acute anterior wall myocardial infarction. Circulation, 93, 1993-1999. doi:10.1161/01.CIR.93.11.1993

[10] Ito, H., Maruyama, A., Iwakura, K., Takiuchi, S., Masuyama, T., Hori, M., Higashino, Y., Fujii, K. and Minamino, T. (1996) Clinical implications of the "no reflow" phenomenon. A predictor of complications and left ventricular remodeling in reperfused anterior wall myocardial infarction. Circulation, 93, 223-228. doi:10.1161/01.CIR.93.2.223

[11] Palade, G.E., Simionescu, M. and Simionescu, N. (1979) Structural aspects of the permeability of the microvascular endothelium. Acta Physiologica Scandinavica, S463, 11-32.

[12] Granger, D.N. (1998) Physiology and pathophysiology of the microcirculation. Dialogues in Cardiovascular Medicine, 3, 123-140.

[13] Granger, D.N. and Korthuis, R.J. (1995) Physiologic mechanisms of postischemic tissue injury. Annual Review of Physiology, 57, 311-332. doi:10.1146/annurev.ph.57.030195.001523

[14] Harrison, D.G. (1997) Cellular and molecular mechanisms of endothelial cell dysfunction. The Journal of Clinical Investigation, 100, 2153-2157. doi:10.1172/JCI119751

[15] Drexler, H. and Hornig, B. (1996) Importance of endothelial function in chronic heart failure. Journal of Cardiovascular Pharmacology, 27, S9-S12. doi:10.1097/00005344-199600002-00003

[16] White, S.K., Hausenloy, D.J. and Moon, J.C. (2012) Imaging the myocardial microcirculation post-myocardial infarction. Current Heart Failure Reports, 9, 282-292. doi:10.1007/s11897-012-0111-y

[17] Camici, P.G. and Crea, F. (2007) Coronary microvascular dysfunction. The New England Journal of Medicine, 356, 830-840. doi:10.1056/NEJMra061889

[18] Chilian, W.M. (1997) Coronary microcirculation in health and disease. Summary of an NHLBI workshop. Circulation, 95, 522-528. doi:10.1161/01.CIR.95.2.522

[19] Krogh, A. (1919) The supply of oxygen to the tissues and the regulation of the capillary circulation. The Journal of Physiology, 52, 457-474.

[20] James, T.N. (1970) The delivery and distribution of coronary collateral circulation. Chest, 58, 183-203. doi:10.1378/chest.58.3.183

[21] De, B.M. and Schaper, W. (1971) Quantitative histology of the canine coronary collateral circulation in localized myocardial ischemia. Life Science, 10, 857-868. doi:10.1016/0024-3205(71)90157-3

[22] Newman, P.E. (1981) The coronary collateral circulation:
Determinants and functional significance in ischemic heart disease. American Heart Journal, 102, 431-445. doi:10.1016/0002-8703(81)90318-5

[23] Kersten, J.R., Pagel, P.S., Chilian, W.M. and Warltier, D.C. (1999) Multifactorial basis for coronary collateralization: A complex adaptive response to ischemia. Cardiovascular Research, 43, 44-57. doi:10.1016/S0008-6363(99)00077-2

[24] Kersten, J.R. and Warltier, D.C. (1999) Modulation of the adaptive response to myocardial ischemia by coexisting disease. American Journal of Physiology, 276, H2268$\mathrm{H} 2270$.

[25] Heil, M. and Schaper, W. (2004) Influence of mechanical, cellular, and molecular factors on collateral artery growth (arteriogenesis). Circulation Research, 95, 449-458. doi:10.1161/01.RES.0000141145.78900.44

[26] Kloner, R.A., Ganote, C.E. and Jennings, R.B. (1974) The "no-reflow" phenomenon after temporary coronary occlusion in the dog. The Journal of Clinical Investigation, 54, 1496-1508. doi:10.1172/JCI107898

[27] Schwartz, B.G. and Kloner, R.A. (2012) Coronary no reflow. Journal of Molecular and Cellular Cardiology, 52, 873-882. doi:10.1016/j.yjmcc.2011.06.009

[28] Ito, H., Okamura, A., Iwakura, K., Masuyama, T., Hori, M., Takiuchi, S., Negoro, S., Nakatsuchi, Y., Taniyama, Y., Higashino, Y., Fujii, K. and Minamino, T. (1996) Myocardial perfusion patterns related to thrombolysis in myocardial infarction perfusion grades after coronary angioplasty in patients with acute anterior wall myocardial infarction. Circulation, 93, 1993-1999. doi:10.1161/01.CIR.93.11.1993

[29] Heusch, G., Kleinbongard, P., Bose, D., Levkau, B., Haude, M., Schulz, R. and Erbel, R. (2009) Coronary microembolization: from bedside to bench and back to bedside. Circulation, 120, 1822-1836. doi:10.1161/CIRCULATIONAHA.109.888784

[30] Luo, A.K. and Wu, K.C. (2006) Imaging microvascular obstruction and its clinical significance following acute myocardial infarction. Heart Failure Reviews, 11, 305312. doi:10.1007/s10741-006-0231-0

[31] Hausenloy, D.J., Baxter, G., Bell, R., Botker, H.E., Davidson, S.M., Downey, J., Heusch, G., Kitakaze, M., Lecour, S., Mentzer, R., Mocanu, M.M., Ovize, M., Schulz, R., Shannon, R., Walker, M., Walkinshaw, G. and Yellon, D.M. (2010) Translating novel strategies for cardioprotection: The Hatter Workshop Recommendations. Basic Research in Cardiology, 105, 677-686. doi:10.1007/s00395-010-0121-4

[32] Schwartz, L.L., Kloner, R.A., Arai, A.E., Baines, C.P., Bolli, R., Braunwald, E., Downey, J., Gibbons, R.J., Gottlieb, R.A., Heusch, G., Jennings, R.B., Lefer, D.J., Mentzer, R.M., Murphy, E., Ovize, M., Ping, P., Przyklenk, K., Sack, M.N., Vander Heide, R.S., Vinten-Johansen, J. and Yellon, D.M. (2011) New horizons in cardioprotection: Recommendations from the 2010 National Heart, Lung, and Blood Institute Workshop. Circulation, 124, 11721179. doi:10.1161/CIRCULATIONAHA.111.032698

[33] Kloner, R.A. and Jennings, R.B. (2001) Consequences of brief ischemia: Stunning, preconditioning, and their clinical implications: Part 1. Circulation, 104, 2981-2989. 
doi:10.1161/hc4801.100038

[34] Hausenloy, D.J. and Yellon, D.M. (2009) Myocardial protection: Is primary PCI enough? Nature Clinical Practice Cardiovascular Medicine, 6, 12-13. doi:10.1038/ncpcardio1371

[35] Reimer, K.A., Jennings, R.B., Cobb, F.R., Murdock, R.H., Greenfield, J.C., Becker, L.C., Bulkley, B.H., Hutchins, G.M., Schwartz Jr., R.P., Bailey, K.R. and Passamani, E.R. (1985) Animal models for protecting ischemic myocardium (AMPIM): Results of the NHLBI cooperative study. Comparison of the unconscious and conscious dog models. Circulation Research, 56, 651-665. doi:10.1161/01.RES.56.5.651

[36] Sharma, V., Bell, R.M. and Yellon, D.M. (2012) Targeting reperfusion injury in acute myocardial infarction: A review of reperfusion injury pharmacotherapy. Expert Opinion on Pharmacotherapy, 13, 1153-1175. doi:10.1517/14656566.2012.685163

[37] Bolli, R. (1992) Postischemic myocardial stunning: Pathogenesis, pathophysiology, and clinical relevance. In: Yellon, D.M. and Jennings, R.B., Eds., Myocardial Protection: The Pathophysiology of Reperfusion and Reperfusion Injury, Raven Press, New York, 1992, 105-149.

[38] Bolli, R. (1992) Myocardial 'stunning' in man. Circulation, 86, 1671-1691. doi:10.1161/01.CIR.86.6.1671

[39] Canty Jr., J.M. and Fallavollita, J.A. (2005) Hibernating myocardium. Journal of Nuclear Cardiology, 12, 104-119. doi:10.1016/j.nuclcard.2004.11.003

[40] Tubau, J.F. and Rahimtoola, S.H. (1992) Hibernating myocardium: A historical perspective. Cardiovascular Drugs and Therapy, 6, 267-271. doi:10.1007/BF00051149

[41] Heusch, G. (1998) Hibernating myocardium. Physiological Reviews, 78, 1055-1085.

[42] Heusch, G., Schulz, R. and Rahimtoola, S.H. (2005) Myocardial hibernation: A delicate balance. American Journal of Physiology: Heart and Circulatory Physiology, 288, H984-H999. doi:10.1152/ajpheart.01109.2004

[43] Beltrami, C.A., Finato, N., Rocco, M., Feruglio, G.A., Puricelli, C., Cigola, E., Quaini, F., Sonnenblick, E.H., Olivetti, G. and Anversa, P. (1994) Structural basis of end-stage failure in ischemic cardiomyopathy in humans. Circulation, 89, 151-163. doi:10.1161/01.CIR.89.1.151

[44] Canty Jr., J.M. and Suzuki, G. (2012) Myocardial perfusion and contraction in acute ischemia and chronic ischemic heart disease. Journal of Molecular and Cellular Cardiology, 52, 822-831. doi:10.1016/j.yjmcc.2011.08.019

[45] Kelly, R.F., Cabrera, J.A., Ziemba, E.A., Crampton, M., Anderson, L.B., McFalls, E.O. and Ward, H.B. (2011) Continued depression of maximal oxygen consumption and mitochondrial proteomic expression despite successful coronary artery bypass grafting in a swine model of hibernation. The Journal of Thoracic and Cardiovascular Surgery, 141, 261-268. doi:10.1016/j.jtcvs.2010.08.061

[46] Liem, D.A., Manintveld, O.C., Schoonderwoerd, K., McFalls, E.O., Heinen, A., Verdouw, P.D., Sluiter, W. and Duncker, D.J. (2008) Ischemic preconditioning modulates mitochondrial respiration, irrespective of the employed signal transduction pathway. Translational Research, 151, 17-26. doi:10.1016/j.trsl.2007.09.007

[47] Page, B., Young, R., Iyer, V., Suzuki, G., Lis, M., Korotchkina, L., Patel, M.S., Blumenthal, K.M., Fallavollita, J.A. and Canty Jr., J.M. (2008) Persistent regional downregulation in mitochondrial enzymes and upregulation of stress proteins in swine with chronic hibernating myocardium. Circulation Research, 102, 103-112. doi:10.1161/CIRCRESAHA.107.155895

[48] Hu, Q., Suzuki, G., Young, R.F., Page, B.J., Fallavollita, J.A. and Canty Jr., J.M. (2009) Reductions in mitochondrial $\mathrm{O}_{2}$ consumption and preservation of high-energy phosphate levels after simulated ischemia in chronic hibernating myocardium. American Journal of Physiology: Heart and Circulatory Physiology, 297, H223-H232. doi:10.1152/ajpheart.00992.2008

[49] Gall Jr., S.A., Maier, G.W., Glower, D.D., Gaynor, J.W., Cobb, F.R., Sabiston Jr., D.C. and Rankin, J.S. (1993) Recovery of myocardial function after repetitive episodes of reversible ischemia. American Journal of Physiology: Heart and Circulatory Physiology, 264, H1130-H1138.

[50] Gallagher, K.P., Matsuzaki, M., Koziol, J.A., Kemper, W.S. and Ross Jr., J. (1984) Regional myocardial perfusion and wall thickening during ischemia in conscious dogs. American Journal of Physiology: Heart and Circulatory Physiology, 247, H727-H738.

[51] Heyndrickx, G.R., Baig, H., Nellens, P., Leusen, I., Fishbein, M.C. and Vatner, S.F. (1978) Depression of regional blood flow and wall thickening after brief coronary occlusions. American Journal of Physiology: Heart and Circulatory Physiology, 234, H653-H659.

[52] Vatner, S.F. (1980) Correlation between acute reductions in myocardial blood flow and function in conscious dogs. Circulation Research, 47, 201-207. doi:10.1161/01.RES.47.2.201

[53] Heusch, G. (2008) Heart rate in the pathophysiology of coronary blood flow and myocardial ischaemia: Benefit from selective bradycardic agents. British Journal of Pharmacology, 153, 1589-1601. doi:10.1038/sj.bjp.0707673

[54] Ross Jr., J. (1991) Myocardial perfusion-contraction matching. Implications for coronary heart disease and hibernation. Circulation, 83, 1076-1083. doi:10.1161/01.CIR.83.3.1076

[55] Kingma, J.G., Simard, D. and Rouleau, J.R. (2011) Modulation of nitric oxide affects myocardial perfusion-contraction matching in anesthetised dogs with recurrent noflow ischemia. Experimental Physiology, 96, 1293-1301. doi:10.1113/expphysiol.2011.060244

[56] DeFily, D.V. (1998) Control of microvascular resistance in physiological conditions and reperfusion. Journal of Molecular and Cellular Cardiology, 30, 2547-2554. doi:10.1006/jmcc.1998.0826

[57] Chilian, W.M. (1991) Microvascular pressures and resistances in the left ventricular subepicardium and subendocardium. Circulation Research, 69, 561-570. doi:10.1161/01.RES.69.3.561

[58] Krug, A., Du Mesnil, D.R. and Korb, G. (1966) Blood 
supply of the myocardium after temporary coronary occlusion. Circulation Research, 19, 57-62. doi:10.1161/01.RES.19.1.57

[59] Staat, P., Rioufol, G., Piot, C., Cottin, Y., Cung, T.T., L'Huillier, I., Aupetit, J.F., Bonnefoy, E., Finet, G., AndreFouet, X. and Ovize, M. (2005) Postconditioning the human heart. Circulation, 112, 2143-2148. doi:10.1161/CIRCULATIONAHA.105.558122

[60] Guo, A.Q., Sheng, L., Lei, X. and Shu, W. (2013) Pharmacological and physical prevention and treatment of no-reflow after primary percutaneous coronary intervention in ST-segment elevation myocardial infarction. Journal of International Medical Research, 41, 537-547. doi:10.1177/0300060513479859

[61] Niccoli, G., Burzotta, F., Galiuto, L. and Crea, F. (2009) Myocardial no-reflow in humans. Cardiology, 54, 281292. doi:10.1016/j.jacc.2009.03.054

[62] Reffelmann, T., Hale, S.L., Li, G. and Kloner, R.A. (2002) Relationship between no reflow and infarct size as influenced by the duration of ischemia and reperfusion. American Journal of Physiology: Heart and Circulatory Physiology, 282, H766-H772.

[63] Reffelmann, T. and Kloner, R.A. (2002) Microvascular reperfusion injury: Rapid expansion of anatomic no reflow during reperfusion in the rabbit. American Journal of Physiology: Heart and Circulatory Physiology, 283, H1099-H1107.

[64] Galiuto, L. and Iliceto, S. (1998) Myocardial contrast echocardiography in the evaluation of viable myocardium after acute myocardial infarction. American Journal of Cardiology, 81, 29G-32G. doi:10.1016/S0002-9149(98)00050-2

[65] Galiuto, L., DeMaria, A.N., May-Newman, K., Del, B.U., Ohmori, K., Bhargava, V., Flaim, S.F. and Iliceto, S. (1998) Evaluation of dynamic changes in microvascular flow during ischemia-reperfusion by myocardial contrast echocardiography. Cardiology, 32, 1096-1101. doi:10.1016/S0735-1097(98)00349-0

[66] Ambrosio, G., Weisman, H.F., Mannisi, J.A. and Becker, L.C. (1989) Progressive impairment of regional myocardial perfusion after initial restoration of postischemic blood flow. Circulation, 80, 1846-1861. doi:10.1161/01.CIR.80.6.1846

[67] Golino, P., Maroko, P.R. and Carew, T.E. (1987) The effect of acute hypercholesterolemia on myocardial infarct size and the no-reflow phenomenon during coronary occlusion-reperfusion. Circulation, 75, 292-298. doi:10.1161/01.CIR.75.1.292

[68] Matsumura, K., Jeremy, R.W., Schaper, J. and Becker, L.C. (1998) Progression of myocardial necrosis during reperfusion of ischemic myocardium. Circulation, 97, 795804. doi:10.1161/01.CIR.97.8.795

[69] Rezkalla, S.H., Dharmashankar, K.C., Abdalrahman, I.B. and Kloner, R.A. (2010) No-reflow phenomenon following percutaneous coronary intervention for acute myocardial infarction: Incidence, outcome, and effect of pharmacologic therapy. Journal of Interventional Cardiology, 23, 429-436.

doi:10.1111/j.1540-8183.2010.00561.x
[70] Murry, C.E., Jennings, R.B. and Reimer, K.A. (1986) Preconditioning with ischemia: A delay of lethal cell injury in ischemic myocardium. Circulation, 74, 11241136. doi:10.1161/01.CIR.74.5.1124

[71] Ovize, M., Baxter, G.F., Di, L.F., Ferdinandy, P., GarciaDorado, D., Hausenloy, D.J., Heusch, G., Vinten-Johansen, J., Yellon, D.M. and Schulz, R. (2010) Post-conditioning and protection from reperfusion injury: Where do we stand? Position paper from the Working Group of Cellular Biology of the Heart of the European Society of Cardiology. Cardiovascular Research, 87, 406-423. doi:10.1093/cvr/cvq129

[72] Yellon, D.M. and Downey, J.M. (2003) Preconditioning the myocardium: From cellular physiology to clinical cardiology. Physiological Reviews, 83, 1113-1151.

[73] Downey, J.M., Davis, A.M. and Cohen, M.V. (2007) Signaling pathways in ischemic preconditioning. Heart Failure Reviews, 12, 181-188. doi:10.1007/s10741-007-9025-2

[74] Hausenloy, D.J. and Yellon, D.M. (2009) Preconditioning and postconditioning: Underlying mechanisms and clinical application. Atherosclerosis, 204, 334-341. doi:10.1016/j.atherosclerosis.2008.10.029

[75] Lu, Y.Z., Wu, C.C., Huang, Y.C., Huang, C.Y., Yang, C.Y., Lee, T.C., Chen, C.F. and Yu, L.C. (2012) Neutrophil priming by hypoxic preconditioning protects against epithelial barrier damage and enteric bacterial translocation in intestinal ischemia/reperfusion. Laboratory Investigation, 92, 783-796. doi:10.1038/labinvest.2012.11

[76] Ko, J.K. and Cho, C.H. (2011) Adaptive cytoprotection and the brain-gut axis. Digestion, 83, 19-24. doi:10.1159/000323400

[77] Meng, R., Asmaro, K., Meng, L., Liu, Y., Ma, C., Xi, C., Li, G., Ren, C., Luo, Y., Ling, F., Jia, J., Hua, Y., Wang, X., Ding, Y., Lo, E.H. and Ji, X. (2012) Upper limb ischemic preconditioning prevents recurrent stroke in intracranial arterial stenosis. Neurology, 79, 1853-1861. doi:10.1212/WNL.0b013e318271f76a

[78] Koch, S., Sacco, R.L. and Perez-Pinzon, M.A. (2012) Preconditioning the brain: Moving on to the next frontier of neurotherapeutics. Stroke, 43, 1455-1457. doi:10.1161/STROKEAHA.111.646919

[79] Lynch III, C. (1999) Anesthetic preconditioning: Not just for the heart? Anesthesiology, 91, 606-608. doi:10.1097/00000542-199909000-00007

[80] Minguet, G., Joris, J. and Lamy, M. (2007) Preconditioning and protection against ischaemia-reperfusion in non-cardiac organs: A place for volatile anaesthetics? $E u-$ ropean Journal of Anaesthesiology, 24, 733-745. doi:10.1017/S0265021507000531

[81] Ma, X.J., Zhang, X.H., Li, C.M. and Luo, M. (2006) Effect of postconditioning on coronary blood flow velocity and endothelial function in patients with acute myocardial infarction. Scandinavian Cardiovascular Journal, 40, 327-333. doi:10.1080/14017430601047864

[82] Laskey, W.K., Yoon, S., Calzada, N. and Ricciardi, M.J. (2008) Concordant improvements in coronary flow reserve and ST-segment resolution during percutaneous coronary intervention for acute myocardial infarction: A benefit of postconditioning. Catheterization and Cardio- 
vascular Interventions, 72, 212-220.

[83] Laude, K., Beauchamp, P., Thuillez, C. and Richard, V. (2002) Endothelial protective effects of preconditioning. Cardiovascular Research, 55, 466-473. doi:10.1016/S0008-6363(02)00277-8

[84] Reffelmann, T. and Kloner, R.A. (2002) Is microvascular protection by cariporide and ischemic preconditioning causally linked to myocardial salvage? American Journal of Physiology: Heart and Circulatory Physiology, 284, H1134-H1141.

[85] Zhao, Z.Q., Corvera, J.S., Halkos, M.E., Kerendi, F., Wang, N.P., Guyton, R.A. and Vinten-Johansen, J. (2003) Inhibition of myocardial injury by ischemic postconditioning during reperfusion: Comparison with ischemic preconditioning. American Journal of Physiology: Heart and Circulatory Physiology, 285, H579-H588.

[86] Kaeffer, N., Richard, V., Francois, A., Lallemand, F., Henry, J.P. and Thuillez, C. (1996) Preconditioning prevents chronic reperfusion-induced coronary endothelial dysfunction in rats. American Journal of Physiology, 271, H842-H849.

[87] Richard, V., Kaeffer, N., Tron, C. and Thuillez, C. (1994) Ischemic preconditioning protects against coronary endothelial dysfunction induced by ischemia and reperfusion. Circulation, 89, 1254-1261. doi:10.1161/01.CIR.89.3.1254

[88] Skyschally, A., Walter, B. and Heusch, G. (2012) Coronary microembolization during early reperfusion: Infarct extension, but protection by ischaemic postconditioning. European Heart Journal. doi:10.1093/eurheartj/ehs434

[89] Whittaker, P. and Przyklenk, K. (1994) Reduction of infarct size in vivo with ischemic preconditioning: Mathematical evidence for protection via non-ischemic tissue. Basic Research in Cardiology, 89, 6-15. doi:10.1007/BF00788673

[90] Freixa, X., Bellera, N., Ortiz-Perez, J.T., Jimenez, M., Pare, C., Bosch, X., De Caralt, T.M., Betriu, A. and Masotti, M. (2012) Ischaemic postconditioning revisited: Lack of effects on infarct size following primary percutaneous coronary intervention. European Heart Journal, 33, 103-112. doi:10.1093/eurheartj/ehr297

[91] Sorensson, P., Saleh, N., Bouvier, F., Bohm, F., Settergren, M., Caidahl, K., Tornvall, P., Arheden, H., Ryden, L. and Pernow, J. (2010) Effect of postconditioning on infarct size in patients with ST elevation myocardial infarction. Heart, 96, 1710-1715. doi:10.1136/hrt.2010.199430

[92] Herrmann, J., Kaski, J.C. and Lerman, A. (2012) Coronary microvascular dysfunction in the clinical setting: From mystery to reality. European Heart Journal, 33, 2771-2781. doi:10.1093/eurheartj/ehs246

[93] Dwivedi, G., Janardhanan, R., Hayat, S.A., Lim, T.K., Greaves, K. and Senior, R. (2010) Relationship between myocardial perfusion with myocardial contrast echocardiography and function early after acute myocardial infarction for the prediction of late recovery of function. International Journal of Cardiology, 140, 169-174. doi:10.1016/j.ijcard.2008.11.052

[94] Hayat, S.A. and Senior, R. (2008) Myocardial contrast echocardiography in ST elevation myocardial infarction: Ready for prime time? European Heart Journal, 29, 299314. doi:10.1093/eurheartj/ehm621

[95] Bolognese, L., Carrabba, N., Parodi, G., Santoro, G.M., Buonamici, P., Cerisano, G. and Antoniucci, D. (2004) Impact of microvascular dysfunction on left ventricular remodeling and long-term clinical outcome after primary coronary angioplasty for acute myocardial infarction. Circulation, 109, 1121-1126. doi:10.1161/01.CIR.0000118496.44135.A7

[96] Dwivedi, G., Janardhanan, R., Hayat, S.A., Swinburn, J.M. and Senior, R. (2007) Prognostic value of myocardial viability detected by myocardial contrast echocardiography early after acute myocardial infarction. Cardiology, 50, 327-334. doi:10.1016/j.jacc.2007.03.036

[97] Posa, A., Pavo, N., Hemetsberger, R., Csonka, C., Csont, T., Ferdinandy, P., Petrasi, Z., Varga, C., Pavo, I.J., Laszlo Jr., F., Huber, K. and Gyongyosi, M. (2010) Protective effect of ischaemic preconditioning on ischaemia/reperfusion-induced microvascular obstruction determined by on-line measurements of coronary pressure and blood flow in pigs. Thrombosis and Haemostasis, 103, 450-460. doi:10.1160/TH09-03-0165

[98] Hoffman, J.I. (1995) Heterogeneity of myocardial blood flow. Basic Research in Cardiology, 90, 103-111. doi:10.1007/BF00789440

[99] Hoffman, J.I.E. (1987) A critical view of coronary reserve. Circulation, 75, 1-6.

[100] Austin, R.E.J., Aldea, G.S., Coggins, D.L., Flynn, A.E. and Hoffman, J.I.E. (1990) Profound spatial heterogeneity of coronary reserve. Discordance between patterns of resting and maximal myocardial blood flow. Circulation Research, 67, 319-331. doi:10.1161/01.RES.67.2.319

[101] Bassingthwaighte, J.B., King, R.B. and Roger, S.A. (1989) Fractal nature of regional myocardial blood flow heterogeneity. Circulation Research, 65, 578-590. doi:10.1161/01.RES.65.3.578

[102] Kingma Jr., J.G., Simard, D. and Rouleau, J.R. (2005) Comparison of neutron activated and radiolabeled microsphere methods for measurement of transmural myocardial blood flow in dogs. Journal of Thrombosis and Thrombolysis, 19, 201-208. doi:10.1007/s11239-005-1201-4

[103] Alhaddad, I.A., Kloner, R.A., Hakim, I., Garno, J.L. and Brown Jr., E.J. (1996) Benefits of late coronary artery reperfusion on infarct expansion progressively diminish over time: relation to viable islets of myocytes within the scar. American Heart Journal, 131, 451-457. doi:10.1016/S0002-8703(96)90522-0

[104] Fearon, W.F., Aarnoudse, W., Pijls, N.H., De, B.B., Balsam, L.B., Cooke, D.T., Robbins, R.C., Fitzgerald, P.J., Yeung, A.C. and Yock, P.G. (2004) Microvascular resistance is not influenced by epicardial coronary artery stenosis severity: Experimental validation. Circulation, 109, 2269-2272. doi:10.1161/01.CIR.0000128669.99355.CB 